\section{The Emerging STEM Paths and Science Identities of Hispanic/Latinx College Students: Examining the Impact of Multiple Undergraduate Research Experiences}

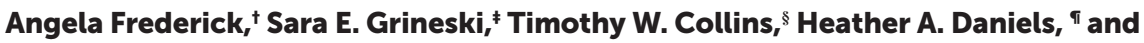 \\ Danielle X. Morales"** \\ +University of Texas at El Paso, El Paso 79968; ‘University of Utah, Salt Lake City, UT 84112; \\ 'University of Utah, Salt Lake City, UT 84112; 'University of California Merced, Merced 95340; \\ "University of Texas at El Paso, El Paso, TX 79968
}

\begin{abstract}
This study reports findings from 19 interviews with Hispanic/Latinx students participating in a university-wide, multiyear program designed to retain students from underrepresented backgrounds in science, technology, engineering, and mathematics (STEM) at a Hispanic-serving institution. We focus on the impact that having multiple opportunities to engage in faculty-mentored, cocurricular undergraduate research experiences (UREs) had on students' STEM paths in college and the cultivation of their science identities. In addition to professional and psychosocial benefits, our findings suggest that having the opportunity to spend multiple summers in UREs at partnering institutions away from home helped to strengthen Hispanic/Latinx students' comfort levels with being away from their families and helped them recognize the broad range of opportunities available to them for graduate school.
\end{abstract}

\section{INTRODUCTION}

Faculty-mentored undergraduate research experiences (UREs) are regarded as a "high-impact practice" for college students, and the benefits of these experiences in keeping students in the science, technology, engineering, and mathematics (STEM) pipeline are well documented (Kuh et al., 2010). In fact, UREs are found to be particularly beneficial in retaining first-generation and underrepresented minority college students (URMs) in STEM (Falconer, 2008; and McNair, 2013; Finley and McNair, 2013; Jones et al., 2010; Haeger and Fresquez, 2016). Yet we still have much to learn about what specific aspects of UREs are beneficial and how programs and interventions can capitalize on evidence-based practices to better retain Hispanic/Latinx students in the STEM pipeline. This study reports findings from 19 interviews with Hispanic/Latinx students participating in a university-wide, multiyear program designed to retain students from underrepresented groups in STEM at a Hispanic-serving institution. We focus on the impact that having multiple opportunities to engage in faculty-mentored, cocurricular UREs had on students' STEM paths in college and the cultivation of their science identities. ${ }^{1}$

\section{BACKGROUND}

Much attention has been given to the importance of increasing diversity in STEM disciplines, as students of color, including Hispanics/Latinx populations, are

${ }^{1}$ Though scholars generally prefer the term "Latinx," our participants identify as "Hispanic," due to preferences in this particular region of the United States. We therefore use the more encompassing term "Hispanic/Latinx" throughout the article to acknowledge both identity preferences.
Stanley M. Lo, Monitoring Editor Submitted Aug 24, 2020; Revised Nov 17, 2020; Accepted Jan 28, 2021

CBE Life Sci Educ June 1, 2021 20:ar18 DOI:10.1187/cbe.20-08-0191

*Address correspondence to: Danielle X. Morales (xdeng2@utep.edu).

(C) 2021 A. Frederick et al. CBE-Life Sciences Education ( 2021 The American Society for Cell Biology. This article is distributed by The American Society for Cell Biology under license from the author(s). It is available to the public under an Attribution-Noncommercial-Share Alike 3.0 Unported Creative Commons License (http://creativecommons.org/licenses/ by-nc-sa/3.0)

"ASCB®" and "The American Society for Cell Biology ${ }^{\circledR}$ " are registered trademarks of The American Society for Cell Biology. 
underrepresented at every stage in the STEM pipeline (National Science Foundation [NSF], 2017). Of particular interest to scholars is how to strengthen the science identities of members of underrepresented groups as they move through high school and into college, as science identity is correlated with better retention rates. Theorists have argued "identity" has become more salient in late modernity, as young people have an increasingly wider range of possibilities when constructing their identities and as work has become more central to their sense of self compared with earlier generations (Holland et al., 1998; Gee, 2000). Specific to STEM, science identity has been defined and operationalized in different ways, but it broadly refers to the degree to which one sees oneself, and is recognized by others, as a "science person" (Carlone and Johnson, 2007). Science identity includes internal processes, such as an interest in science and motivation to pursue a career in STEM disciplines (Vincent-Ruz and Schunn, 2018). Science identity also includes social processes, such as socialization into the norms of particular STEM disciplines and recognition by others that one is a "science person" (Carlone and Johnson, 2007; Vincent-Ruz and Schunn, 2018). Science identity has been conceptualized as overlapping with, but not synonymous with, career choices (Hazari et al., 2010). Making choices that lead one to a successful career in STEM often emerges from the motivations and socialization one receives; conversely, an underdeveloped science identity can lead to decisions that steer a student away from a STEM career path.

Those concerned with the underrepresentation of women and racial/ethnic minority groups in STEM have focused on science identity as a linchpin for understanding the process by which certain students persist in STEM careers, while others leave the pipeline. Researchers have used science identity as an analytic lens to understand the processes that lead to underrepresentation in STEM by gender (Hazari et al., 2010), race/ ethnicity (Estrada et al., 2018), social class (Archer et al., 2015), and the intersections of all these categories (Carlone and Johnson, 2007; Hazari et al., 2013). Evidence suggests groups underrepresented in STEM disciplines are less likely to identify as "science people," which can lead to decisions that ultimately lead members of these groups to exit the STEM pipeline (Hazari et al., 2013). These divergent paths appear as early as elementary school and persist through high school (Hazari et al., 2010). Furthermore, college seems to be a critical time when science identities have the potential to be nurtured or disrupted (Carlone and Johnson, 2007; Hazari et al., 2013).

\section{UREs}

Scholars focused on identity in late modernity point to the critical role that communities play in fostering the course of young people's identity development within educational settings (Holland et al., 1998; Gee, 2000; Urrieta, 2007). For college students, participating in research provides critical experiences within communities of practice that can profoundly shape these students' identities and career paths. Thus, it may come as no surprise that the positive outcomes of faculty-mentored UREs for college students are well documented. College students who participate in UREs report a higher level of academic engagement, more experiences with deep learning, and a strengthened set of professional skills (Kuh et al., 2010).

Specific to STEM, college students report higher levels of confidence in their ability to do scientific work (Russell et al.,
2007) and a deepened sense that science has the potential to make positive social change (Weinberg et al., 2018) when they participate in UREs. These benefits also translate into tangible long-term outcomes. Students who participate in UREs are more likely to earn graduate degrees in STEM disciplines and to obtain jobs in STEM fields (Jones et al., 2010; Eagan et al., 2013; Graham et al., 2013; Wilson et al., 2018).

Researchers distinguish between two types of UREs. Cocurricular UREs are apprenticeship models in which students are mentored in research by faculty in a research setting outside the traditional classroom, while course-based UREs incorporate research into courses (Hernandez et al., 2018). The current study focuses on the impact of cocurricular UREs. The benefits conferred through mentoring relationships with faculty are among the most important advantages undergraduate students gain through cocurricular research (Lopatto, 2010; Hernandez et al., 2018). The deepened ties between students and faculty that can be generated in UREs help to cultivate undergraduate students' science identities, including their ability to think and work like scientists (Russell et al., 2007; Thiry et al., 2012; Wilson et al., 2018; Joshi et al., 2019). Through direct interaction with faculty in research settings outside of the classroom, students experience increased social capital as faculty mentor them in professional skills, career goals, and psychosocial development (Aikens et al., 2016).

With the overall benefits of UREs now well documented, scholars are turning their attention to identifying how and when these experiences are most beneficial for college students. Jones et al. (2010), for example, point to the importance of starting research early in college. Other studies have found that the longevity of UREs improves student outcomes, including helping students cultivate a more sophisticated understanding of the research process and the professional skills expected in their disciplines (Thiry et al., 2012). Finally, Hernandez et al. (2018) found that only those UREs that require 10 and more hours a week of work and those that last two or more semesters in duration generate positive outcomes, such as increasing the likelihood that students will graduate with a bachelor's degree in a STEM-related field. Researchers are also turning their attention to examining the quality of mentoring that students experience in UREs . (Daniels et al., 2016), for example, found that the quality of mentoring mattered more than the duration of the UREs in generating positive gains among students at a Hispanic-serving institution.

Scholars have only recently begun to investigate the factors that generate negative research experiences for STEM undergraduates and the impacts of these negative experiences (Thiry and Laursen, 2011; Cooper et al., 2019; Limeri et al., 2019). Limeri and colleagues (2019) identified types of negative mentoring experiences of life science undergraduate students participating in UREs, including "abuse of power" (such as belittling and name-calling), "lack of career and technical guidance," and "unequal treatment of student researchers" (such as displaying favoritism for specific students). These researchers found that students often felt dependent upon the faculty mentor as a gatekeeper to the future science careers they desired, which made it difficult for the students to extract themselves from negative mentoring relationships.

In this study, we focus on an underexamined topic in the literature on UREs in STEM fields. We examine how multiple research experiences shaped students' STEM paths in college and their science identities. Researchers investigating a range of 
career and educational contexts have advocated for the importance of cultivating a network of mentors whose strengths and weaknesses complement one another (Allen and Eby, 2010), and students participating in STEM UREs are often mentored by both a faculty member and graduate students in the lab context (Joshi et al., 2019; Thiry and Laursen, 2011). Yet, while research has pointed to the importance of multiple mentors, we investigate how multiple UREs in distinct research contexts might shape students' STEM experiences.

\section{Hispanic/Latinx College Students and STEM}

Hispanic/Latinx populations remain underrepresented at every stage of the STEM pipeline (NSF, 2017). Broader patterns of lower college attainment contribute to the underrepresentation of Hispanic/Latinx groups in STEM. Hispanics/Latinx young adults are less likely to attend 4-year colleges compared with their white counterparts in the United States. Furthermore, evidence suggests that Hispanic/Latinx students, compared with white students, tend to attend college close to home. These decisions are thought to be the result of both financial constraints and a preference to remain close to their families (Ovink and Calogrides, 2015; Ovink et al., 2018). In areas such as the U.S.Mexico border, where few highly ranked colleges are available locally, the preference to remain at home leads to a pattern of undermatching for high-achieving Hispanic/Latinx students, whereby they tend to attend colleges for which they are overqualified (Ovink and Calogrides, 2015; Ovink et al., 2018; Hillman, 2016). Subsequently, these decisions may shape students' decisions on whether or not to pursue graduate school. In addition to lower rates of college attendance, other factors that play a role in the underrepresentation of Hispanic/Latinx populations in STEM have been identified. Most notably, Hispanic/Latinx college students, like other URM students, often need additional encouragement and supports to cultivate their science identities, as differences in academic preparation, not having role models from their home communities, and subtle messages of devaluation within predominantly white institutions all contribute to a lack of comfort in STEM (Carlone and Johnson, 2007; Frederick et al., 2018; Grineski et al., 2018) and may ultimately steer these students away from STEM careers.

UREs are particularly important in increasing the numbers of URMs in STEM fields (Estrada et al., 2018), as they have the potential to offset some of the challenges these students face in cultivating their science identities. At the undergraduate level, UREs often serve as a stopgap for both Black and Hispanic/Latinx college students, sustaining their interest in pursuing STEM majors and their intention to persist into STEM-related graduate programs (Russell et al., 2007; Schultz et al., 2011; Eagan et al., 2013). Findings from several studies suggest that faculty mentorship through UREs offers even more benefits for URM and first-generation college students than for traditionally privileged college students (Finley and McNair, 2013; Haeger and Fresquez, 2016), including the opportunity to build competitive skills, such as publishing in scientific journals (Grineski et al., 2018; Morales et al., 2017). Overall, UREs are found to improve the likelihood that Hispanic/Latinx students will earn a bachelor's degree in a STEM field (Jones et al., 2010; Hernandez et al., 2018).

The benefits of participating in UREs for Hispanic/Latinx college students also extend beyond their undergraduate education. While white students from more privileged socioeconomic backgrounds might enter college already intending to pursue graduate studies, UREs can be a critical intervention for URM students (Russell et al., 2007). Villarejo et al. (2008) found that URM college students, including Hispanic/Latinx students, started thinking about graduate school for the first time after participating in UREs. Other studies have found that URM students who participate in UREs, including Hispanic/Latinx students, are more likely to report intention to enter STEM-related graduate programs than URM students who have not participated in undergraduate research (Russell et al., 2007; Schultz et al., 2011; Eagan et al., 2013). This sustained interest in STEM careers translates into concrete benefits. Studies have shown that Hispanic/Latinx students who participated in UREs were more likely to actually go on to pursue terminal degrees in their STEM fields (Hernandez et al., 2018; Wilson et al., 2018) and to be working in a STEM field 6 years after graduation (Hernandez et al., 2018) than Hispanic/Latinx students who did not participate in UREs while in college. Russell et al. (2007) found that these positive benefits were most pronounced for Hispanic/Latinx college students compared with other racial/ ethnic groups.

\section{METHODS}

In this study, we report findings from interviews conducted with 19 Hispanic/Latinx college students participating in a university-wide undergraduate program designed to increase the number of students entering STEM research careers. We here forth refer to this program as "Excel." The students participating in this study were selected in one cohort of the Excel program. To provide a substantial layer of protection of confidentiality to participating students, we refrain from reporting the year these students entered the program and have assigned pseudonyms to the program name, participants, and any individuals named within participant quotes. The university that houses the program is a Hispanic-serving institution located in a majority-Hispanic community on the U.S.-Mexico border. With the goal of preparing college students for graduate school and eventual placement in STEM research careers, Excel offers a multitude of resources for participating students, beginning with a full scholarship for the duration of college and a monthly living stipend. Excel offers multiple professional development workshops each academic year, as well as a peer-mentoring program. One of the distinguishing features of the program, however, is that it is designed to offer students multiple opportunities to engage in UREs. In their first year, students engage in course-based UREs, in which research is embedded in the class. In addition, students participate in cocurricular summer research programs each year in college, as well as cocurricular research at their home institution during the academic year. Figure 1 illustrates the major Excel components students participate in as they move through their time in college.

Students are selected into the Excel program through a merit-based application process. Most enter the program as firstyear college students, though a few join in their second and third years of college. At the time of this writing, these students have been interviewed three times, once during their first semester in college, once during their second-year summer research experience, and once during their third year. Because we are interested in students' perspectives across multiple 


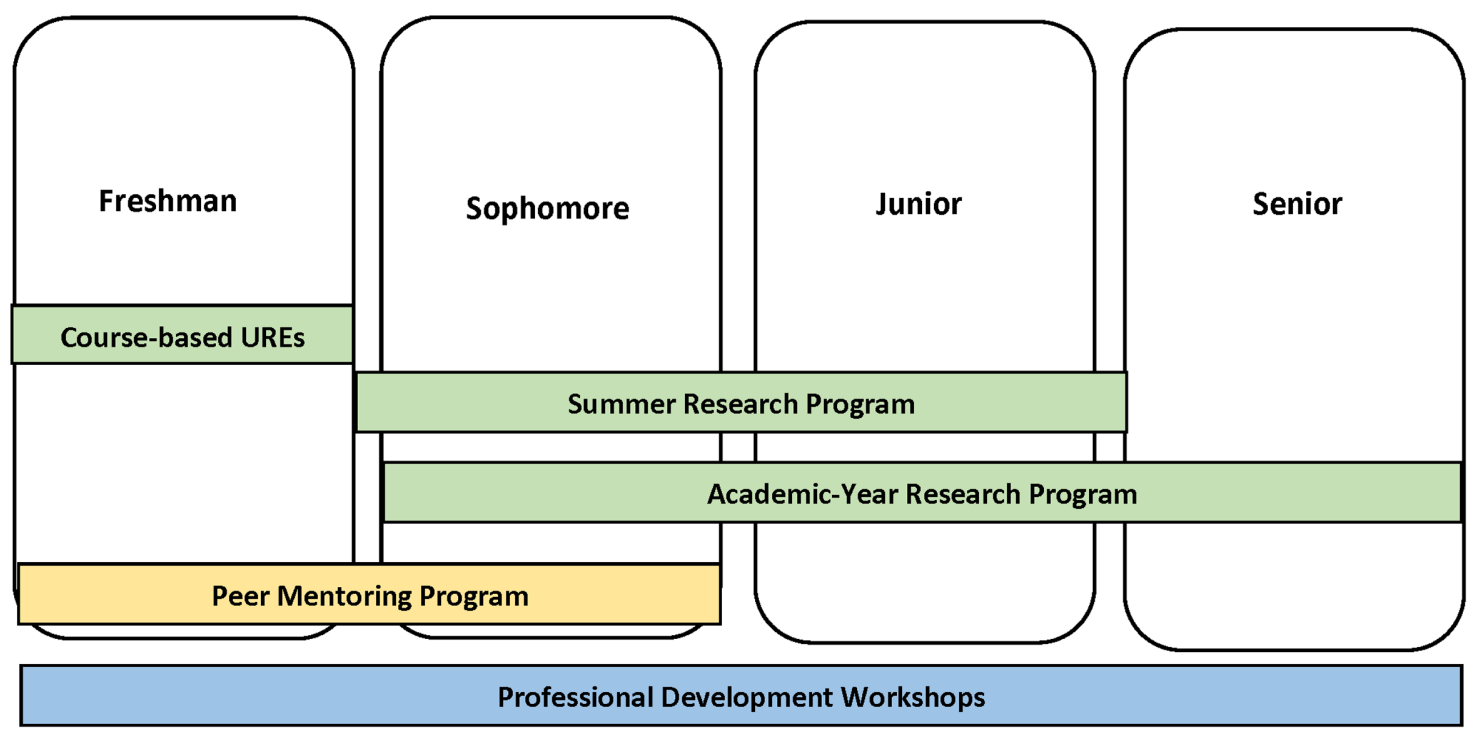

FIGURE 1. Excel program training sequence overview.

faculty-mentored UREs, we focus here on the third round of interviews we conducted with students during their junior year.

TABLE 1. Sample demographics

\begin{tabular}{lcc}
\hline Student characteristics & Number & Percent of total \\
\hline Sex & & \\
$\quad$ Female & 12 & 63.2 \\
$\quad$ Male & 7 & 58.3 \\
Major & & \\
$\quad$ Biochemistry & 2 & 10.5 \\
Biological sciences & 4 & 21.1 \\
Chemistry & 2 & 10.5 \\
Electrical engineering & 2 & 10.5 \\
Engineering & 3 & 15.8 \\
Kinesiology & 1 & 0.0 \\
Mechanical engineering & 2 & 10.5 \\
Psychology & 2 & 10.5 \\
Physics & 1 & 5.3 \\
Household income & & \\
\$10,000-\$19,999 & 4 & 21.1 \\
\$20,000-\$29,999 & 3 & 15.8 \\
\$30,000-\$39,999 & 1 & 5.3 \\
\$40,000-\$49,999 & 2 & 10.5 \\
\$50,000-\$59,999 & 3 & 15.8 \\
\$60,000-\$7,999 & 1 & 5.3 \\
\$75,000-\$99,999 & 3 & 15.8 \\
\$100,000-\$149,999 & 2 & 10.5 \\
First-generation college student & 5 & 26.3 \\
Career status & & \\
STEM-related graduate program & 4 & 21.1 \\
STEM-related postbaccalaureate & 2 & 10.5 \\
$\quad$ program & 5 & \\
$\quad$ gurrently applying for STEM-related & & \\
Working in healthcare & 5.3 \\
Non-STEM graduate program & & \\
Left Excel before graduation & 5.3 \\
\hline
\end{tabular}

Table 1 displays the demographic makeup of the sample. We collected demographic data for all participants when they entered the program. Twelve of the participants identify as "female," and seven identify as "male." All participants identify as "Hispanic." Students report a wide range of social class backgrounds. Four participants ( $21.1 \%$ of the sample) report family household incomes of less than $\$ 20,000$, while five participants (36.8\%) report household incomes of $\$ 75,000$ or above. Participants' majors included engineering, chemistry, biological sciences, psychology, and public health sciences. All participants expressed an interest in pursuing careers in STEM-related fields. Five participants (26.3\% of our sample) are first-generation college students.

At the time of this writing, this cohort of students is still in a transitional stage. All graduated less than a year ago. Thus, at this early stage, we cannot yet report conclusive findings about students' career trajectories or make predictive claims about the importance of having multiple UREs on long-term career outcomes. We can report, however, that four of the sample participants are currently in highly selective graduate programs in STEM-related disciplines, and one is in a master's program not related to STEM. Two participants are in postbaccalaureate programs at nationally renowned health research institutions. Six participants are currently applying for graduate programs in STEM-related fields while working or volunteering in their STEM fields of interest. One participant is working in a healthcare position but did not indicate plans to apply for graduate school. Five of the participants ultimately left the Excel program after their junior-year interview but before graduation-four due to grade point averages falling below the required 3.3 minimum, and one because she accepted a position at an engineering company.

The research team worked collaboratively to develop the interview guide, which was semistructured. We agreed upon a set list of questions; however, the interviewer probed or asked additional questions when topics arose that were not covered in the interview guide. The interview guide included questions touching on themes we identified as being potentially salient for the participants, including mentoring and internship 
experiences, family support, science identity, and their plans for the future. Questions included: "Can you picture yourself as a scientist or researcher?," "How does your family feel about you pursuing a career in STEM?," and "How does your relationship with your research mentor this summer compare with your relationship with your mentor last summer?"

The interviews were conducted both in person and via Skype, depending upon participant availability. At the time of their third-year interviews, participants were all still in the Excel program. Students provided informed consent for the research as they entered the program and again before each individual interview. All students participating in the program in this cohort agreed to be interviewed. Interviews were conducted by H.D. and were transcribed by A.F.

Data were coded using both deductive and inductive approaches. The first author (A.F.) conducted an initial round of coding to capture all passages referring to faculty-mentored research. Each member of the team then analyzed the quotes from this parent node, and we discussed emergent themes as a group. The themes presented in the findings represent the patterns agreed upon as significant by all members of the research team. Though our original questionnaire did not ask deductive questions designed to elicit specific responses about the importance of having multiple research opportunities, our inductive coding process led us to identify this as an important theme in participants' interviews. After collectively recognizing this theme, we collaboratively identified components of the theme of multiple research experiences, which included: developing professional and psychosocial skills such as becoming comfortable living away from home during summer research experiences, serving as a rescue net for students who had profoundly negative first experiences, and helping students gain clarity about their professional priorities.

Because this is a qualitative analysis with a small sample size, the strength of our study is illuminating how students interpret their own experiences in UREs. Thus, we are interested in examining how these students make meaning of their research experiences and their overall STEM paths in light of their multiple UREs. Because we do not yet have evidence about these students' ultimate career paths at this stage in the longitudinal study, we will not use our findings to make predictive claims about how multiple research opportunities determine students' retention in STEM fields.

The research team includes three women professors, one professor who is a man, and one woman graduate student. Four members of the research team identify as white, and one of the woman professors identifies as Asian. The graduate student on our research team conducted the interviews. While her identity as a white woman who does not speak Spanish might have posed a limitation, her status as a younger, first-generation college student herself, who attended the same university as an undergraduate student, likely eased barriers that students might have otherwise felt if they had been interviewed by one of the professors on the research team.

\section{FINDINGS}

\section{Developing Professional and Psychosocial Skills}

We began each junior-year interview with a broad prompt for participants: "Tell me about your experiences in Excel now that you're two years into the program." The majority of students
(16 out of 19) named the opportunity to participate in faculty-mentored research as one of the most valuable aspects of their experiences in Excel. This is notable, given that the broad prompt did not direct students to reflect specifically on faculty-mentored research. Consistent with prior research on the benefits of UREs, students discussed both the professional skills they developed and the psychosocial benefits they experienced as they have worked in research labs under a faculty mentor. Specifically, three students discussed the skills they have gained in writing and publishing papers and presenting at conferences. Three students identified networking with other scientists as an important opportunity they have gained from their UREs. Three students discussed how their applications for graduate school were strengthened through the research opportunities they had as Excel students. Two students used the word "confidence" when describing the most important benefits of their research experiences, and four students said that their commitments to pursuing careers in research were solidified through their research experiences.

Most salient to our investigation of the impact of multiple research opportunities, however, was the fact that students identified specific benefits they gained from having the opportunity to work in more than one research lab through the Excel program. When asked what he learned from his summer research experiences, Estefan emphasized the benefits of gaining exposure to a variety of lab environments:

The stuff I do in my lab back in [our university], it's really different to what I'm doing now and what I did last summer. ... So you kind of get exposed to different research methods in different areas. Like last summer I did something related to cancer. This year I'm doing like treating cell culture. So kind of all of it's in the area of biomedical research, but at the same time, really different experiments and really different people in each lab. So you kind of learn in every experience.

Mariana used the word "dynamic" to describe how working in multiple lab environments has strengthened her résumé and her research skills. "I really like getting tidbits of experience, right? So I can go to a different city every year, you know? For three years, I can work on three different projects, and it adds to a different dynamic. It makes me a more dynamic candidate, or it makes me a more dynamic researcher "cause I have all these different experiences."

When asked how her relationships with faculty have changed since her freshman year, Luciana explained how she benefited from having a network of faculty mentors with whom she could seek guidance.

When I was a freshman, ... whenever I had a problem or a question, the only person I would go to would be Dr. [Jenkins]. But now I know like who gives the best advice regarding this, regarding that. Like I know that a professor that is not in [Excel] won't give me the best advice with [Excel]. Or a professor who doesn't have a background in certain things won't give me the best advice on that. So I just, I have more relationships with more people than I had when I was a freshman.

Jacki named the multiple research experiences she has had as central to her gratitude about being part of the Excel 
program. "If I hadn't been in [Excel], I probably wouldn't have done two summer research programs, probably wouldn't have done research as an undergrad, probably wouldn't have published, and would have to be working."

Excel offers participating students the opportunity to spend their summers in labs at other universities in different regions of the country. While attending college away from one's hometown is a common experience for middle-class white students, research finds Hispanic/Latinx students tend to attend college while living at home (Ovink and Kalogrides, 2015). Of these interviewed students, all but one was from the metropolitan area surrounding the university. Thus, the Excel summer research experiences offered these students the new opportunity to live and spend time in multiple locations and to experience the resources and campus cultures at other universities. In fact, Michelle argued these opportunities compelled her to apply for the Excel program in the first place:

When I applied to [Excel], the thing I was most excited about was the summer research opportunities and kind of going away from [our university] and being able to go to a different institution and see what it's like somewhere else and be really incorporated into a research program. So, I definitely would say that it's been my favorite experience of all, of [Excel], of everything that we've done. It's given me an opportunity to, not only make connections and make friends, but also to see different institutions, what their research standards are like, what type of labs do they have, just learning about their programs, their graduate programs. Yeah, I think it's given me a lot of great opportunities, and I definitely think that it's been the best part.

Karen also had the following to say about the impact of her summer research experiences:

I've learned, for sure, how to get out of my comfort zone and not be afraid to talk to someone. That's for sure. Second of all, I've learned so many different [research] techniques that I've acquired and I carry with me, you know, still to this day. Third of all, doing summer research kind of helps you, if you're considering like MD or $\mathrm{PhD}$ like I am right now. It kind of helps you realize if you truly want to go to graduate school and get a PhD and if you truly want to be a researcher. Because I think the summer research programs really show you what research is like. And especially I think leaving [our university], you get to see so many different things.

Having practice getting out of their comfort zones can be transformative for students. Luciana noticed a difference in herself during her second summer living away from home to do her research experience compared with her first summer away:

And like this summer, it was a lot easier than last summer. Like last summer, I remember crying a lot and being all sad because I was by myself. And this summer, I didn't feel like that. ... Like last summer, one of my biggest struggles was I was by myself and that felt lonely. That I really missed my family. That I was homesick and just like really, I guess, a little bit depressed. I don't know. It was just one of the biggest things I remember feeling. ... That's one of the things I spent most of my time thinking about, like how I wished I was with my mom or with my family.
Luciana is currently applying for graduate school. At the time of her junior-year interview, Luciana was already reflecting upon how much she had grown in her ability to be away from her family and what this would mean when she applied for graduate school:

This summer has been completely different. ... So this summer, that definitely hasn't been a struggle, and so I know I've grown in that sense. So I know that when I go off to grad school and I'm by myself, I'll be fine. I won't be all sad like I was last summer.

\section{A Rescue Net}

Most of the students interviewed named the summer research opportunities as the most valuable aspect of the Excel program. Yet 16 out of 19 participants described at least one of their UREs using negative descriptions. While identifying the degree and type of negative experiences is beyond the scope of this article, descriptions we characterize as negative include qualifiers such as "hostile," "isolating," and "incredibly frustrating." Four of the students interviewed explicitly explained that the opportunity to have more than one URE gave them access to multiple faculty mentors, which served a critical function-as a rescue net that kept them in the STEM pipeline in the wake of profoundly negative first research experiences.

Lucas's first faculty mentor relationship could be characterized as "abusive" according to Limeri et al.'s typology (2019). Lucas described his first summer research experience as "really sour," "really bad," and "terrible" at various points in his interview. His faculty mentor exhibited behavior that caused Lucas severe emotional distress. Lucas shared multiple stories about working in his first research lab. We share one story here to convey his experience. Lucas described the last meeting he and his faculty mentor had to discuss the research poster Lucas was to present to the Excel program on his summer project.

Wednesday, I have a meeting with her to show her my poster. ... She like just grills me. Like she's yelling at me. ... She's cursing me out, which is like weird for me, especially for a freshman. ... I personally felt like my poster was pretty good. But ... she just like glanced at it, and she was like, "This is shit." And I'm like, "You didn't even look at it. Like, come on." ... Of course like, again, I was like a freshman, and I was pretty impressionable. And ... I feel like that's something that's already like, well, I'm barely getting into research and now you're already like telling me I'm nothing basically. It was hard.

This experience caused Lucas to fall into a deep depression. "Like I was just kind of like in my bed, and I was like, everything sucks. Like it was bad." Lucas also told administrators in Excel that he could not continue to work in the lab; they agreed and facilitated him finding a new research placement. "I actually told them, I was like, 'I will not survive if you keep me in that lab for two more months, because I'm already like at the edge, like I'm not feeling well."”

This distressing first research experience caused Lucas to re-evaluate his career goals. He had been engaging in lab-based research with the intent of using those experiences to prepare him for medical school and a career as a doctor. Lucas needed to find a new research experience, as the Excel program requires 
that he conduct academic-year research to keep this scholarship. Because he could not continue working in his first lab, Lucas reached out to a science professor with whom he had taken a course his first year. "And so by the end, I mean, I decided to email my ... professor, my spring ... professor, because I was like, I know he does research. I always considered doing research with him. I might as well like ask to see like what he's doing. I asked. He was like, sure, let's meet. And I met with him, and now I'm here. And now I've found like success in my research. And I like my research. So, I can't complain [laughs]." This positive second research experience ultimately kept Lucas in the science research pipeline. It is notable that, during his negative research experience, Lucas had the ability to reach out for assistance from administrators in the Excel program, which prevented him from feeling dependent upon the abusive faculty mentor as a gatekeeper to his STEM career (Limeri et al., 2019). It is also notable that Excel required Lucas to find another research lab, which discouraged him from giving up on STEM entirely after his negative experience.

Lucas is now in graduate school at a prestigious university, pursuing work in a STEM field. He effusively praised his second mentor for helping him to develop his professional skills and passion for the field.

He's ... just like really, really supportive. And he keeps an eye out for like things I could tentatively apply to. And he's done well in ... maximizing my success and my chances at grad school. I mean, he's allowing me to do this publication. And I remember talking to him, and he's like, "I could write this publication, but I'd rather you write it. Because if you're not writing it, what good is it doing you?" ... And so he's just been really good in the vein of like really encouraging me to ... try things that I may not be comfortable with.

Lucas's story illuminates the importance of having the opportunity to cultivate multiple mentors. Navigating a moment of severe emotional stress due to being mistreated by a faculty mentor temporarily disrupted Lucas's science identity and could have meant the end to Lucas's trajectory in the STEM pipeline. But having the support of administrators in the Excel program and the opportunity to carve out a second research experience repaired Lucas's science identity and kept him on a career path in STEM.

Luciana worked for 2 years in a lab she later described as "a hostile environment." Consistent with Limeri and colleagues' (2019) classification of "unequal treatment" as a negative mentoring practice, Luciana identified the ways favoritism practiced by the faculty member generated a sense of jealousy and competition among both graduate and undergraduate students. At first, Luciana was unable to name the problematic dynamics in the lab, because she did not have other experiences with which to compare. She explained, "So, and, well, I guess unfortunately, I had never had a job before. And I really didn't know how to go about it. And I had never been in a lab before. So, my freshman year, I really didn't notice all the issues that I had or that were present in that lab."

The summer after her freshman year, Luciana participated in a summer research experience at a university in a nearby state. Through this URE, Luciana found a mentor she describes as "the best mentor ever." The lab environment was more collabo- rative and less hostile. The positive experience Luciana had in her summer research experience caused her to clearly evaluate the negative environment in her first academic-year lab. "My sophomore year, when I came back from my summer lab, ... like my eyes just opened. Like I had been blind the whole time. And my eyes just lit up. I'm like, "Wow, this is how I'm living." Luciana's story illuminates the importance of offering multiple research experiences to give students the opportunity for comparison. Without the summer research experience, Luciana would not have gained the perspective to recognize that her first research experience at her home institution was hostile.

Two other students, Alma and Jacki, did not describe their first research experiences as hostile or emotionally distressing as Lucas and Luciana did. But both Alma and Jacki experienced strain due to lackluster experiences in their first labs. Alma described having two negative research experiences, which diminished her commitment to pursuing a career as a science researcher. She characterized the problems in her academic-year research lab and her first summer research lab as related to a lack of autonomy in the lab. The importance of Alma's third, more positive, research experience was illuminated when we asked her whether she sees herself as a scientist.

Alma:

Yeah, I mean, yeah, I really enjoy it. I was kind of like not liking it after last summer and after my experience in Dr. [Stevens'] lab. So, it was like, I'm doing research, but I don't really enjoy it."

Interviewer:

So, then, can you picture yourself as a scientist or researcher?

Alma went on to describe the difference between her first two experiences and her third and how having autonomy in her research has renewed her motivation. She said, "But, honestly, ... I'm running every single experiment. ... So, I feel like, once you prove yourself and you show them that you can do it, that's when it gets better. Which is why I started liking research again."

Similar to Alma, Jacki's third lab experience helped to solidify her desire to become a scientist. And like Alma, the chance to have a sense of ownership over a project made the difference in her third research experience.

Interviewer:

Right now, can you picture yourself as a scientist or researcher?

Jackie:

Yeah, I mean, I feel like I'm starting to picture myself doing it. Before I always thought like, "Oh, how am I gonna do this?" Like I never even plan my own things. But, seeing a lot of the grad students and how they think, it's like, it makes me realize that they just kind of brainstorm a lot. And it makes me think that, you know, it's doable. You can do it. You just have to work hard. So, yeah, like I guess before I just didn't see myself, because I didn't know how to go about designing your own experiment. At [our university] it was just kind of like my mentor would tell me what to do. And it's like, I never, I felt like I wasn't doing research. I was just being a lab tech. Whereas here, I feel more like a scientist. And I like that feeling. So, now I know that I do like research more than I thought I did. 
Jacki's quote illuminates the importance of quality mentorship in helping students to cultivate their science identities. Jacki experienced autonomy within a supported structure, which solidified her commitment to science.

\section{Gaining Professional Clarity}

During each interview, we asked students: "Can you picture yourself as a scientist or researcher?" Eighteen out of 19 participants said they could picture themselves as scientists or researchers. Notably, 13 of the 19 students, without prompting, named their experiences participating in undergraduate research as the reason for their "science identities." As part of their emerging science identities, having multiple faculty-mentored research experiences appeared to help many of the students gain clarity about both their professional interests and what they want in a working environment. This clarity is evident, not only in the interviews of students who had negative experiences, but also among those who had positive or at least satisfactory experiences.

Lucas and Luciana, whose profoundly negative experiences we described in the previous section, were both able to clarify their professional interests and their expectations for their working environments through their subsequent positive mentoring relationships. Lucas's emotionally distressing first lab-based research experience caused him to re-evaluate his commitment to going to medical school, a change he said has made him much happier. In fact, Lucas said he is grateful for the negative research experience, because it set him on a path toward a career in a different type of research, with which he is much happier.

So I feel, like looking back on it, I, I mean, I'm kind of thankful for it. Like it sounds really weird to be like thankful for ... being mistreated. ... But, no, I think just like large-scale what I gained from it, ... I decided to do what I wanted to do. ... That was like a big thing for me, mostly because like I feel like my parents really expected me to go to medical school. ... And I think after that I was like, I can't. Like I'm not happy. I need to do what I want to do.

In Luciana's case, her negative experience also helped her gain clarity about her professional path. Luciana's academic-year faculty mentor stopped speaking to her after she decided to pursue the summer opportunity elsewhere, instead of staying in his lab over the summer. This caused Luciana a great deal of distress at the time. Fortunately, Luciana's new mentor Dr. White was able to help Luciana negotiate her emotions surrounding her decision to leave that first lab. As Luciana explained,

But, I think that I, like Dr. [White] said, she told me that once I had the bad experience, and now I'm gonna be able to identify it a lot quicker if I do end up somewhere else in the same situation. So, that gives me a little bit of comfort. Even if I do end up in a terrible place in the future, I know that I will be able to identify it. It won't be like, oh, I've never, is this how a lab is supposed to be? No. Like I know that for sure now.

It is noteworthy that, more than a year later, Lucas and Luciana were able to reframe their negative experiences as learning opportunities with the guidance of their new faculty mentors.
Several students discussed how they learned to clarify the difference between prioritizing the topic of research or the specific mentor and their lab environment when selecting between research opportunities. Isabel, for example, explained that she liked the research project better in her second summer research experience, but she preferred the mentoring style of the faculty mentor in her first summer research lab: "So, I definitely like this project a lot more. But, I loved my mentor last summer. I had a great mentor last summer who was really good at teaching and who was really patient and who understood that I was like a freshman. ... And she was just always there for me."

Similarly, while Mariana loved her first summer research experience, she decided to take a different research opportunity her second summer to do research that she believed would more closely align with her career goals. Yet Mariana came to learn that the lab environment might be more important to her than the specific research project. As she explained: "And I think last summer ... I learned that I had fun doing what I didn't want to do, you know what I mean?" Hoping to gain experience in a field more closely aligned with her interests, Mariana made the decision to join a different lab for her next summer URE. She found, however, that the new lab had a different culture where she did not feel as supported. Yet Mariana learned to gain perspective as she struggled to make sense of her two different summer research experiences. "And I don't want to look at it as a negative experience, right? Cause I still learned, I still learned. Different techniques. I learned new information, like a whole different field of biology, right? But I think I learned more about me."

Having multiple UREs helped both Isabel and Mariana to articulate their priorities in a science lab. Being able to recognize the nuances in different STEM subfields, lab cultures, and mentoring styles is an important component of science identity, as it enables these students to make strategic decisions as they move along their career paths in STEM. Mariana pointed to this deeper importance when she said, "I think I learned more about me."

Not all of the gains in clarity had to do with overcoming negative experiences. Mia, for example, discussed the value of multiple research experiences in terms of being able to work with faculty and graduate mentors at different stages in their careers and in different stages of research. She said, "I think it's really helped me, mostly because I've seen I guess like every aspect of research." Like I've seen someone just starting and then like someone who's almost going to finish their research. So I can see like the building of the person like within the years of grad school." Seeing mentors at different stages in their careers helped Mia to demystify the research process. She continued, "It's also helped me to see that I'm not going to get everything on the first try per se. Like it's going to take a while for me to come up with different things or to get the results that I actually want to get."

Taken together, these students' quotes exemplify how they gained clarity about their respective disciplines of interest by experiencing a variety of STEM research environments. Through their multiple UREs, these students cultivated a nuanced understanding of the multiple, and sometimes competing, factors that make up a work environment in STEM-related fields.

\section{DISCUSSION}

The students interviewed for this study identified a number of benefits they garnered from participating in multiple 
cocurricular UREs through the Excel program, both at their home institution during their academic year and in their summer internships. They reported gains in professional skills, such as networking, writing papers, and presenting research. They also reported psychosocial benefits, including gaining perspective about difficult experiences and clarity about what is important to them in the working environment. Not only did students discuss positive gains from having the opportunity to be mentored by multiple faculty mentors in different settings, but they also reported appreciating the opportunity to gain experience in a variety of STEM disciplines in different universities and regions of the country and being able to see researchers with very different working styles at various stages in the STEM pipelines. All of these gains have been identified as important to building students' science identities, as they increase their confidence, competence, and sense of being a "science person."

The cultivation of science identity through multiple faculty-mentored research experiences remains underexamined in the literature. Asking students to reflect on various science tasks (predominately through quantitative surveys) does not fully capture the day-to-day processes of cultivating and/or strengthening students' science identities in college. Through students' reflection on the totality of their experiences in Excel, it is clear that opportunities such as autonomously running experiments in the lab, coauthoring publications, and being validated by significant actors in their field contributed to their identification as scientists and/or researchers. Building technical skills and networking with important actors are well-known positive outcomes of URE participation (Carlone and Johnson 2007; Hazari et al., 2013). This study adds to the existing literature by showing how the opportunity for students to participate in multiple and different research settings can help students form a better understanding of how they fit into STEM fields. While quantitative studies have demonstrated increased competence in tasks associated with science identity, this qualitative study illuminates the complex processes that play out over multiple research experiences and contribute to students' identification as scientists, because students articulate these processes in their own words.

Our findings suggest that having the opportunity to spend multiple summers in UREs at partnering institutions away from home strengthened students' comfort levels with being away from their families and helped students recognize the broad range of opportunities available to them for graduate school. This benefit may be particularly salient for Hispanic/Latinx students, who are more likely to attend schools close to home, even if the school is an undermatch (Ovink and Calogrides, 2015; Ovink et al., 2018). It is too early to make conclusive claims about these students' career trajectories. It is significant, however, that six out of 19 participants are currently in highly selective graduate and/or postbaccalaureate programs, and five others are currently applying for graduate programs, away from their home communities. These numbers, along with students' own interpretations of the impact of their summer UREs at other institutions, suggest that summer research experiences away from home can be a critical opportunity that will assist Hispanic/Latinx students in developing the skills and orientation toward pursuit of graduate STEM degrees at institutions for which the students are well matched.

Our data also reveal that negative research experiences can have a monumental impact on college students' career decisions, as well as their overall mental health. For the students in Excel, having the opportunity (and requirement) to have multiple UREs with different faculty mentors, and even at different institutions, served as a "rescue net" that kept them in the STEM pipeline. These findings suggest that offering multiple experiences within structured programs can be essential to the retention of URM students in the STEM pipeline. Of course, it would be ideal to ensure that all student experiences with faculty mentors are positive; however, this is likely a tall order for programs serving many students at large research universities. In addition to initiatives designed to enhance faculty mentoring practices, offering students the chance to recover and reassess the impact of one or two negative experiences appears to be critical. Limeri and colleagues (2019) found that undergraduate students in negative research environments often felt dependent upon the faculty mentor for the keys to their future in STEM fields. Under a structured program such as Excel, it might be the case that this sense of dependence is lessened, as students have multiple chances to pursue research in different lab environments. As we continue to examine mechanisms to recruit and retain Hispanic/Latinx students in the STEM pipeline, the protective factor of having more than one undergraduate research opportunity should be further considered. In addition, it might be important for programs like Excel to offer opportunities for students to reflect upon their emerging science identities and professional skills as they move through these different research environments.

Though we argue here that having multiple UREs confers positive benefits, it is important to emphasize that these benefits are likely not to be realized without quality mentored research experiences. One of the unique characteristics of the structure of the Excel program is that students experience both UREs with longer durations during the academic year combined with summer research experiences. Furthermore, students in Excel have the opportunity to stay in the same lab across multiple academic years and during summers, should they choose to do so. Thus, though Excel appears to offer students a chance to restart and reflect through multiple UREs, the program simultaneously nurtured long-term faculty-mentored relationships when students found these to be beneficial. Though we cannot examine this question using our particular sample, it is possible that having too many short-term UREs without adequate time for adjustment and acculturation into the lab might produce negative, rather than positive, effects. Furthermore, it was the quality mentoring experiences students had that generated positive outcomes for these students. Multiple negative experiences are likely to contribute to the loss of talented Hispanic/Latinx students from the STEM pipeline.

Finally, our study points to the importance of examining the impact of negative research experiences in future research. While characterizing the types of negative research experiences and their consequences is beyond the scope of this analysis, our findings demonstrate that it was not uncommon for students to have lackluster, or even powerfully negative, UREs. While we have explored the importance of multiple research opportunities in buffering the impact of these negative experiences, our study points to important future avenues of research. In particular, more research is needed to investigate the consequences of these negative experiences for URM students, such as Hispanic/ Latinx students, compared with students from more privileged backgrounds. Limeri and colleagues (2019) suggest that the 
impact of negative experiences might be greater for URM students, who are less likely to enter college with a commitment to pursuing graduate school in STEM. In addition, more research is needed to identify effective programming that will enhance faculty mentoring practices, while shielding students from the consequences of negative research experiences.

\section{REFERENCES}

Aikens, M. L., Sadselia, S., Watkins, K., Evans, M., Eby, L. T., \& Dolan, E. L. (2016). A social capital perspective on the mentoring of undergraduate life science researchers: An empirical study of undergraduate-postgraduate-faculty triads. CBE-Life Sciences Education, 15(2), ar16. https:// doi.org/10.1187/cbe.15-10-0208

Allen, T. D., \& Eby, L. T. (Eds.). (2010). The Blackwell handbook of mentoring: A multiple perspectives approach. West Sussex, UK: Wiley.

Archer, L., Dawson, E., \& DeWitt, J. (2015). "Science capital:" A conceptual, methodological, and empirical argument for extending Bourdieusian notions of capital beyond the arts. Research in Science Teaching, 52(7) 922-948.

Carlone, H. B., \& Johnson, A. (2007). Understanding the science experiences of successful women of color: Science identity as an analytic lens. Journal of Research in Science Teaching, 44(8), 1187-1218.

Cooper, K. M., Gen, L. E., Akeeh, B., Clark, C. E., Hunter, J. S., Roderick, T. B. ... \& Brownell, S. E. (2019). Factors that predict life sciences student persistence in undergraduate research experiences. PLOS ONE, 14, 1-30.

Daniels, H. A., Grineski, S. E., Collins, T. W., Morales, D. X., Morera, O., \& Echegoyen, L. (2016). Factors influencing student gains from undergraduate research experiences at a Hispanic-serving institution. CBE-Life Sciences Education, 15(3), ar30. https://doi.org/10.1187/cbe.15-07-0163

Eagan, M. K., Hurtado, S., Chang, M. J., Garcia, G. A., Herrera, F. A., \& Garibay, J. C. (2013). Making a difference in science education: The impact of undergraduate research programs. American Educational Research Journal, 50(4), 683-713.

Estrada, M., Hernandez, P. R., \& Schultz, P. W. (2018). A longitudinal study of how quality mentorship and research experience integrate underrepresented minorities into STEM careers. CBE-Life Sciences Education, 17(1), ar9. https://doi.org/10.1187/cbe.17-04-0066

Falconer, J., \& Holcomb, D. (2008). Understanding undergraduate research experiences from the student perspective: A phenomenological study of a summer student research program. College Student Journal, 42(3), 869-878.

Finley, A., \& McNair, T. (2013). Assessing underserved students' engagement in high-impact practices. Washington, DC: Association of American Colleges and Universities. Retrieved November 4, 2019, from www.aacu. org/assessinghips/documents/ TGGrant_Final_11_13.pdf.

Frederick, A., Daniels, H. A., Grineski, S. E., \& Collins, T. W. (2019). "I've never felt like that inhibits anything:" The gendered frameworks of Hispanic women college students in a STEM program. Gender \& Education, 21(5), $646-663$.

Gee, J. P. (2000). Chapter 3: Identity as an analytic lens for research in education. Review of Research in Education, 25(1), 99-125.

Graham, M. J., Frederick, J., Byars-Winston, A., Hunter, A. B., \& Handelsman, J. (2013). Increasing persistence of college students in STEM. Science, 341(6153), 1455-1456.

Grineski, S. E., Daniels, H., Collins, T. W., Morales, D. X., Frederick, A., \& Garcia, M. (2018). The conundrum of social class: Disparities in publishing among STEM students in undergraduate research programs at a Hispanic majority institution. Science Education, 102, 283-303

Haeger, H., \& Fresquez, C. (2016). Mentoring for inclusion: The impact of mentoring on undergraduate researchers in the sciences. CBE-Life Sciences Education, 15(3), ar36. https://doi.org/10.1187/cbe.16-01-0016

Hazari, Z., Sadler, P. M., \& Sonnert, G. (2013). The science identity of college students: Exploring the intersection of gender, race, and ethnicity. Journal of College Science Teaching, 42(5), 82-91.

Hazari, Z., Sonnert, G., Sadler, P. M., \& Shanahan, M. C. (2010). Connecting high school physics experiences, outcome expectations, physics identity, and physics career choice: A gender study. Journal of Research in Science Teaching, 47(8), 978-1003.
Hernandez, P. R., Woodcock, A., Estrada, M., \& Schultz, P. W. (2018). Undergraduate research experiences broaden diversity in the scientific workforce. BioScience, 68(3), 204-211.

Hillman, N. W. (2016). Geography of college opportunity: The case of education deserts. American Educational Research Journal, 53(4), 987-1021.

Holland, D., Lachicotte, W., Skinner, D., \& Cain, C. (1998). Identity and agency in cultural worlds. Cambridge, MA: Harvard University Press.

Jones, M. T., Barlow, A. E. L., \& Villarejo, M. (2010). Importance of undergraduate research for minority persistence and achievement in biology. Journal of Higher Education, 81(1), 82-115.

Joshi, M., Aikens, M. L., \& Dolan, E. L. (2019). Direct ties to a faculty mentor related to positive outcomes for undergraduate researchers. BioScience, 69(5), 389-397.

Kuh, G. D., Kinzie, J., Schuh, J. H., \& Whitt, E. J. (2010). Student success in college: Creating conditions that matter. In Kuh, G. D. (Ed.). San Francisco: Jossey-Bass.

Limeri, L. B., Asif, M. Z., Bridges, B. H. T., Esparza, D., Tuma, T. T., Sanders, D., ... \& Dolan, E. L. (2019). "Where's my mentor?!" Characterizing negative mentoring experiences in undergraduate life science research. CBE-Life Sciences Education, 18(4), ar61. https://doi.org/10.1187/cbe.19-02-0036

Lopatto, D. (2007). Undergraduate research experiences support science career decisions and active learning. CBE-Life Sciences Education, 6(4), 297-306.

Lopatto, D. (2010). Undergraduate research as a high-impact student experience. Peer Review, 12(2), 27-30.

Morales, D. X., Greneski, S. E., \& Collins, T. W. (2017). Increasing research productivity in undergraduate research experiences: Exploring predictors of collaborative faculty-student publications. CBE-Life Sciences Education, 16(3), ar42. https://doi.org/10.1187/cbe.16-11-0326

National Science Foundation. (2017). Women, minorities, and persons with disabilities in science and engineering: 2017 (Special Report NSF 17-310). Retrieved July 19, 2020, from www.nsfgov/statistics/wmpd

Ovink, S. M., \& Calogrides, D. (2015). No place like home? Familism and Latino/a-white differences in college pathways. Social Science Research, 52, 219-235.

Ovink, S. M., Calogrides, D., Nanny, M., \& Delaney, P. (2018). College match and undermatch: Assessing student preferences, proximity, and inequality in post-college outcomes. Research in Higher Education, 59, 553-590.

Russell, S. H., Hancock, M. P., \& McCullough, J. (2007). Benefits of undergraduate research experiences. Science, 316, 548-549.

Schultz, W., Hernandez, P. R., Woodcock, A., Estrada, M., Chance, R. C., Aguilar, M., \& Serpe, R. T. (2011). Patching the pipeline: Reducing disparities in the sciences through minority training programs. Educational Evaluation \& Policy Analysis, 33(1), 95-114

Thiry, H., \& Laursen, S. L. (2011). The role of student-advisor interactions in apprenticing undergraduate researchers into a scientific community of practice. Journal of Science Education and Technology, 20, 771-784.

Thiry, H., Weston, T. J., Laursen, S. L., \& Hunter, A. B. (2012). The benefits of multi-year research experiences: Differences in novice and experienced students' reported gains from undergraduate research. CBE-Life Sciences Education, 11(3), 260-272.

Urrieta, L. (2007). Figured worlds and education: Introduction to the special issue. Urban Review, 39(2), 107-116. doi: 10.1007/s11256-007-0051-0

Villarejo, M., Barlow, A. E., Kogan, D., Veazey, B. D., \& Sweeney, J. K. (2008). Encouraging minority undergraduates to choose science careers: Career paths survey results. CBE-Life Sciences Education, 7(4), 394409

Vincent-Ruz, P., \& Schunn, C. D. (2018). The nature of science identity and its role as the driver of student choices. International Journal of STEM Education, 5, ar48.

Weinberg, A. E., Trott, C. D., \& Sample, L. B. (2018). Who produces knowledge? Transforming undergraduate students' views of science through participatory action research. Science Education, 102, 11551175.

Wilson, A. E., Pollock, J. E., Billick, I., Domingo, C., Fernandez-Figueroa, E. G., Nagy, E. S., ... \& Summers, A. (2018). Assessing science training programs: Structured undergraduate research programs make a difference. BioScience, 68(7), 529-534. 